\title{
Antecedents of knowledge sharing in communities of practice
}

Katja Zboralski

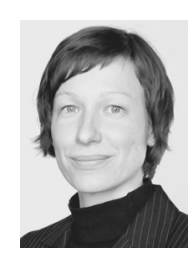

Katja Zboralski is a Postdoctoral Research Fellow based at the Institute of Technology and Management, Berlin University of Technology, Berlin, Germany.

\begin{abstract}
Purpose - Communities of practice (CoPs) have gained a great deal of attention from practitioners and scholars alike. However, critical antecedents of knowledge sharing in CoPs have not been fully researched yet. Particularly, empirical results are still scarce. The aim of this paper is to analyse the role of community members' motivation to participate in CoPs, the importance of the community leader and the influence of management support.
\end{abstract}

Design/methodology/approach - In order to test the proposed hypotheses data from 222 CoP members from different communities of a multinational company gathered in a large sample quantitative survey, using partial least square structural equations modelling.

Findings - The research results show that a leading facilitator and an appropriate managerial support influence interaction processes in CoPs positively.

Research limitations/implications - The impact of motivational and managerial factors on knowledge sharing processes in CoPs is conceptualized and tested. With regard to further CoP research, the developed scales may serve as a basis for future empirical studies. Furthermore, the type of knowledge handled in the CoP as well as assessments from community leaders could enhance the understanding of learning and knowledge generation in CoPs.

Practical implications - New insights with respect to the management of CoPs in corporate practice, answering questions such as "What motivates people to participate in CoPs?" or "How to lead knowledge workers in CoPs?" are found.

Originality/value - On the basis of a large sample empirical analysis these research results give evidence for the importance of different antecedents of interaction processes in CoPs.

Keywords Knowledge sharing, Leadership, Team management

Paper type Research paper

\section{Introduction}

In today's knowledge-based economy, an organization's ability to strategically leverage knowledge has become a crucial factor for global competitiveness. As a consequence, a growing number of organizations, especially in knowledge-intensive industries, has introduced knowledge management systems in order to use the resource knowledge more effectively and efficiently (Davenport and Prusak, 1998; Probst et al., 1999). Particularly, the integration of existing knowledge, e.g. captured in the expertise of employees, and the generation of new knowledge are of paramount importance for the success of organizations (Nonaka and Takeuchi, 1995; Teigland, 2003). In this context, many organization utilize "communities of practice" (CoPs), a concept that has recently gained great attention from practitioners and scholars alike (e.g., Pan and Scarbrough, 1998; Thompson, 2005; Wenger et al., 2002). Knowledge networks like CoPs are increasingly seen as central means to foster and enhance learning, knowledge sharing and integration in organizations (e.g. Brown and Duguid, 1991; Lesser and Storck, 2001).

The CoP concept has undergone significant changes during the past years. Originally introduced in the context of Lave and Wenger's seminal research towards a "social theory of 
learning", a CoPs was seen as an "active system about which participants share understandings concerning what they are doing and what that means" (Lave and Wenger, 1991: 98). The increasing popularity of the concept in corporate practice brought about a managerially oriented interpretation of the term: A CoP can be defined as a group of people in an organization who interact with each other across organizational units or organizational boundaries due to a common interest or field of application in order to learn and support one another, create, spread, retain, and use knowledge relevant to the organization (e.g. Andriessen and Verburg, 2004; Wenger et al., 2002). In general, CoPs are self-emerging and self-organizing networks in which everyone can participate (Wenger, 1998a). However, in the context of knowledge management initiatives many organizations - in particular multinational companies in knowledge-intensive industries - deliberately establish CoPs (APQC, 2000). Further, existing informal networks are strategically supported.

As the concept of CoPs has been discussed not until the last decade, research on CoPs has been emphasized as an important, yet underdeveloped field (Hislop, 2003; Teigland, 2003). Prior research is so far mostly based on qualitative case studies (e.g., Gherardi et al., 1998; Gongla and Rizzuto, 2001; Kimble and Hildreth, 2005). Despite the emphasized importance of motivation, management and leadership in the context of knowledge sharing (Mertins et al., 2001), little is known about antecedents of CoP interactions. Therefore, the author addresses following research questions in this paper: Which impact has:

- LISTcommunity members' motivation to participate in CoPs;

- LISTthe community leader; and

- LISTmanagement support on the interaction processes in CoPs?

By answering these questions this study contributes to CoP and knowledge management research in several ways. First, the impact of motivational and managerial factors on knowledge sharing processes in CoPs is analyzed conceptually. Second, a large scale empirical analysis of these proposed relationships is provided. Third, based on the results new insights with respect to the management of CoPs, answering questions such as "What motivates people to participate in CoPs?" or "How to lead knowledge workers in CoPs?" are added. Finally, the author contributes to the knowledge management literature by employing multi-item measures for the constructs of her research model. This approach increases reliability of the results and opens for further empirical research in the context of CoPs.

The paper proceeds as follows: In the next section the research framework is derived based on prior literature. After that the research design of the empirical study is outlined before the findings are presented. The paper concludes with a discussion of the findings and provides both, research and managerial implications.

\section{Research framework}

\section{Interaction processes in communities of practice}

Communities are characterized by mutual relationships and a regular flow of information between the community members enabling the exchange and generation of knowledge and "common practices" (e.g., Lesser and Storck, 2001; Wenger, 1998a). Thereby, communication between community members is the basis for establishing, extending and maintaining relationships with each other. Which features characterize communication between community members?

Reviewing theoretical and empirical work on CoPs as well as related research streams, four features seem to be of paramount importance for "good" interaction within a group of people:

1. trust;

2. cohesion;

3. communication climate; and

4. interaction frequency (see Zboralski, 2007 for a detailed discussion). 


\section{"The CoP concept has undergone significant changes during the past years."}

Interpersonal trust is a necessary prerequisite for transferring and generating knowledge in CoPs (Ardichvili et al., 2003; Bogenrieder and Nooteboom, 2004). This is in line with knowledge management research (e.g. Davenport and Prusak, 1998), team research (e.g. Costa et al., 2001; Jarvenpaa and Leidner, 1999), and research on networks (e.g. Inkpen and Tsang, 2005). Cohesion between members affects the willingness to spent time, effort, and energy on interacting with other community members. Previous research on work teams has emphasized the importance of strong intergroup relations on team effectiveness (e.g. Guzzo and Shea, 1992; Holland et al., 2000). Communication climate is also considered as an important feature of interaction in CoPs. Again, results from team research confirm that open, constructive and accurate communication has a positive impact on team results (Bogenrieder and Nooteboom, 2004; Hoegl and Gemuenden, 2001). Further, interaction frequency characterizes interaction processes (Bogenrieder and Nooteboom, 2004).

Trust, cohesion, and communication climate are features of the quality of CoP interactions. Thus, these three aspects are regarded as dimensions of interaction quality. Based on the argumentation that interaction frequency is an important but not sufficient prerequisite for efficient, high-quality knowledge sharing, the author distinguishes between the frequency and quality of interaction processes.

\section{Antecedents of interaction processes in communities of practice}

Similar to models of team efficiency (McGrath, 1964) three levels of analysis can be considered for examining antecedents of CoP interaction: member level, concerning specific characteristics of community members; community level, concerning specifics of the community; and organizational level, concerning the characteristics of the organization which "hosts" the CoP. Three factors, one of each level, are considered as important antecedents of community interaction:

1. members' motivation;

2. community leader; and

3. management support.

All three antecedents and their impact on CoP interaction will be discussed in more detail in the reminder of this section.

In order to analyze the impact of CoP interaction processes' antecedents the framework includes three sets of hypothesized relationships: The first set $(\mathrm{H} 1 \mathrm{a}-\mathrm{H} 1 \mathrm{c})$ addresses the interrelation of three different antecedents on the interaction frequency. The second set of hypotheses $(\mathrm{H} 2 \mathrm{a}-\mathrm{H} 2 \mathrm{C})$ is concerned with the relationship of the antecedents and the interaction quality. A third hypothesis $(H 3)$ addresses the relationship of interaction frequency and interaction quality. Together, $\mathrm{H} 1$ and $\mathrm{H} 3$ suggest that interaction frequency mediates the relationship between CoP antecedents and interaction quality. Figure 1 illustrates the path model with the hypothesized relationships.

Generally, individuals are members of a large number of private and professional networks where they participate, share knowledge and experiences (Wenger, 1998a). Every person makes its choice with which persons it shares its knowledge (Teigland and Wasko, 2004). Thereby, the decision to interact with other CoP members is primarily based upon individual interests. Because individuals and their interests vary to a large extent, knowledge sharing is a complex and complicated process (von Krogh, 2002). As participation in CoPs is generally based on voluntary contributions, members' motivation to participate in a CoP becomes a 


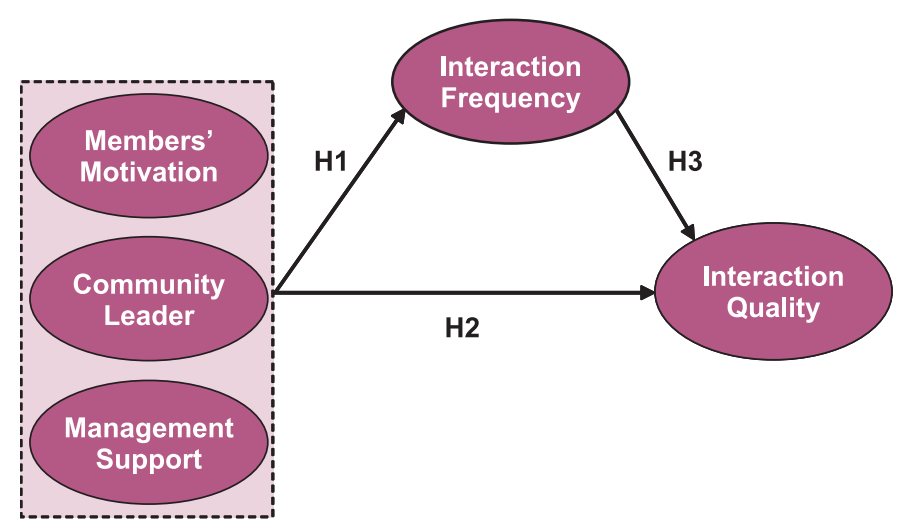

central determinant of CoP interactions (Teigland, 2003). Such motivation can stem from various sources; interest in the topic, the expected benefits of acquiring new knowledge, the objective to build a personal network or to increase one's reputation can be motivational factors (Ardichvili et al., 2003; Wasko and Faraj, 2000). Members who perceive the outcome of CoP activities to be beneficial for themselves and who are motivated by these potential returns and rewards should actively engage in CoP interaction (e.g. Ellis et al., 2004). Hence, a positive relationship between the members' motivation and the frequency/quality of interaction in CoPs is expected:

H1a. Member's motivation to participate in the CoP has a direct positive impact on the interaction frequency in a CoP.

H2a. Member's motivation to participate in the CoP has a direct positive impact on the interaction quality in a CoP.

Socio-psychological research (McGrath, 1964) and innovation research (Allen and Cooney, 1973; Hauschildt and Salomo, 2007) point out that over time individuals take over specific roles which enable and support group processes. Furthermore, knowledge management literature emphasizes the importance of established roles and responsibilities for successful knowledge management projects. In particular, the role of leaders/facilitators has been discussed (e.g. APQC, 2000; Davenport et al., 1998).

Due to the specific characteristics of CoPs community leadership is different from traditional top-down/team management. Whereas functional groups and teams have measurable objectives for which they can be held accountable, CoPs are responsible for "generic" learning and knowledge sharing in specific competence areas (e.g. Lesser and Storck, 2001; Snyder, 1999). As activities in CoPs are informal and highly voluntary, they rely more on the self-motivation and initiative of members and the alignment of members' individual goals with the organization's mission (Snyder, 1999). Nevertheless, assuming that members are intrinsically motivated, the community leader in terms of a facilitator can be regarded as one of the critical contextual success factors of CoPs (APQC, 2000; Moran and Weimer, 2004; Wenger, 1998a). It is the task of the community leader to motivate members to engage in CoP processes, to plan and organize community events, coach new members, or support interactions between members. The better a community leader will fulfil these tasks, the more intensive and better the interaction in the CoP will be. Thus, the author proposes that the community leader plays a substantial role for the activity level and interaction quality in CoPs:

H1b. The community leader has a direct positive impact on the interaction frequency in a CoP.

H2b. The community leader has a direct positive impact on the interaction quality in a CoP. 
Former research has pointed out that the organizational context is crucial for work group success (e.g., Gladstein, 1984; Govindarajan and Gupta, 2001). In the context of knowledge management, management support has been proven to be of major importance (e.g., Hansen et al., 1999). As community interactions depend on resources provided, management support is an important contextual element for every CoP. Further, management's general attitude towards knowledge sharing enables and motivates members "to reach beyond the knowledge they carry in their heads as they go about solving technical problems" (Mohrman et al., 2003, p. 10). Establishing a knowledge management friendly atmosphere, including active promotion of CoPs, will increase peoples' awareness of the necessity to share knowledge in an organization and will encourage CoP interactions (von Krogh, 1998). Thus, a positive relationship between management support and interaction processes in CoPs is postulated:

H1c. Management support has a direct positive impact on the interaction frequency in a CoP.

H2c. Management support has a direct positive impact on the interaction quality in a CoP.

\section{The impact of interaction frequency on interaction quality}

As discussed before, trust, cohesion and communication climate are considered as different aspects which characterize the interaction quality in a CoP. Following the assumption that trust develops through interaction, time can be understood as an important determinant (Inkpen and Tsang, 2005). In particular, the frequency of interaction influences the development of trust between community members. Similarly, the frequency of interaction influences the feeling of sympathy between members of a group and, thus, cohesion (Homans, 1960). Furthermore, interacting frequently over time will give community members the chance to articulate their expectations and demands for a fruitful communication. In sum, all three dimensions of interaction quality are positively influenced by frequent interaction. Thus, following hypothesis is proposed:

H3. Interaction frequency has a direct positive impact on interaction quality in a CoP.

\section{Research design}

\section{Sample and data collection procedures}

To answer the research questions and test the proposed conceptual model the author conducted an empirical study in a multinational company. This company is regarded as a pioneer in knowledge management and had at that time established at least 220 active CoPs covering a wide range of different subjects and practices. Each community has a formally assigned community leader who is in charge of initiating and operating each community. Two hundred and twenty community leaders were contacted in order to verify the age of their $\mathrm{CoP}$ and the number of active community members. Only communities which were active for more than 6 months and had more than 5 active members qualified for participation in the study. Overall, 59 leaders of qualifying communities agreed to participate in this study. The leaders were asked to distribute the questionnaire to the members of their community. As the author can not control to what extent the questionnaire was sent to all community members by the leaders an assessment of the response rate is difficult.

\section{“In today's knowledge-based economy, an organization's ability to strategically leverage knowledge has become a crucial factor for global competitiveness."}


The final sample consists of 222 member questionnaires from 36 communities. Based on the number of active members in these communities as disclosed by the leaders the author is able to cover about 31 percent of all active community members. Due to the semi-formal and dynamic character of CoPs which makes the assessment of the overall number of CoP members difficult, this sample can be considered as a very good representation of the overall population. The average age of the community is 15.2 months, with an average of 73 members. The respondents have been community members for an average of 22.5 months and spent on average 1 to 2 hours per week on their community activities. Average tenure of the respondents with the company is 11.5 years. Neither the duration of participation in the $\mathrm{CoP}$ nor the tenure of the respondents is significantly related to the constructs tested in this study. Potential concerns about retrospective bias and common methods variance were in part ameliorated via the instrument development process which involved careful instrument design in terms of question wording and sequence.

\section{Measures}

To test the proposed hypotheses, measures of each construct were developed using multiple items and Likert-type scales ( $1=$ "not true at all"/"never" to $7=$ "completely true"/("several times a week"). When possible, items and scales previously developed and tested were used. When existing scales could not be used, the author thoroughly developed scales following general guidelines by Churchill (1979). For constructing indexes based on formative indicators the guidelines provided by Diamantopoulos and Winklhofer (2001) were followed. Formal pre-tests were conducted to determine the clarity of the scale items used in the constructs and to obtain preliminary data on the hypotheses. In the pre-tests, 15 community members completed a questionnaire and were involved in follow-up interviews. Their comments and suggestions were incorporated by removing ambiguities and other sources of confusion. Management support is developed and tested as a reflective construct. All other constructs are treated as formative constructs (Bollen, 1989). Interaction quality is a second order construct; treated on the first level as formative construct. Its three dimensions are reflective factors, calculated as the mean over their respective items. The measures are briefly discussed below.

Members' motivation. Members' objectives to participate in the CoP are captured by six items: to learn new things; to pass on own knowledge, to improve my career prospects, to make progress with certain projects, to make my work easier, to improve my contact with colleagues (Ardichvili et al., 2003; Teigland and Wasko, 2004).

Community leader. Six items where used to evaluate to what the extent the community leader handles successfully his tasks: leading the community; motivating the members; planning and organizing the community; coaching and support; communication/information; specialist support (Moran and Weimer, 2004).

Management support. The corporate support for the community is captured by four items: awareness of the importance of CoP work, providing resources, speaking positively to others about CoP activities, support from supervisor.

Interaction frequency. How often members use different instruments and functionalities of the CoP is measured by ten items: face-to-face meeting subgroup, face-to-face meeting whole group, conference call, phone calls with individual members, video conference, virtual collaboration (net meeting), chat, discussion forum/news board, e-mail/mailing list, knowledge base/community workspace.

Interaction quality. This second order construct measures the quality of interaction between CoP members by three factors: Trust is captured by four items adopted from scales previously used by Jarvenpaa and Leidner (1999). Cohesion is captured by five items, communication climate is captured by four items, adopted from scales previously used by Hoegl and Gemuenden (2001). 


\title{
"Trust, cohesion and communication climate are features of the quality of CoP interactions."
}

\begin{abstract}
Method
The level of analysis for testing the hypotheses is the individual community member. Thus, all measures reflect members' perception of $\mathrm{CoP}$ effects on the organisational performance. A measurement model is applied to establish valid and reliable constructs. To test the proposed hypotheses simultaneously and to account for the multi-dimensionality of the factors partial least squares (PLS-graph) is used. This procedure defines coefficients of regression between the factors iteratively and by this manner, it allows to estimate the model simultaneously (Chin, 1998). For reflective factors the author assessed reliability, validity and unidimensionality of the measures using Cronbach's alpha, item-to-total correlations and principal component analysis (Hulland, 1999). For constructing indexes based on formative indicators the authos followed th guidelines provided by Diamantopoulos and Winklhofer (2001). As formative measurement models are based on linear equation systems, collinearity among indicators of formative constructs would affect the stability of indicator coefficients. Hence, multi-collinearity is tested as suggested by Belsley (1991), using SPSS. Validity of the overall model is assessed by the significance levels which result from the T-values from a bootstrapping procedure (Chin, 1998).
\end{abstract}

\section{Results}

\section{Sample statistics}

Table I presents the numbers of items, means, standard deviations, and bivariate correlations among the study variables. Items used for the constructs of the model together with their weights (formative) and factor loadings (reflective) as well as $t$-statistics are reported in Table II.

All shown correlations are significant $(p<0.01)$. The highest correlation between antecedent variables and dependent variables pertains to the relationship of community leader and interaction quality $(r=0.60)$. Management support is highly correlated to both, interaction frequency $(r=0.41)$ and $(r=0.45)$. Interaction frequency shows a positive correlation with interaction quality $(r=0.45)$.

\section{Structural model}

The results from the path model estimating the effects of the independent variables on community interaction frequency and interaction quality are reported in Table III. $R 2$ values of 0.25 and 0.47 for the dependent variables of the model suggest that a moderate part of the variance can be explained. $\mathrm{H1}$, suggesting a positive effect of the three community

\section{Table I Sample statistics and correlations*}

\begin{tabular}{lcccccccc} 
& Number of items & Mean & $S D$ & 1 & 2 & 3 & 4 & 5 \\
\hline 1. Members' motivation & 6 & 4.94 & 1.01 & & & & \\
2. Community leader & 6 & 5.01 & 1.34 & 0.24 & & & \\
3. Management support & 4 & 4.58 & 1.59 & 0.24 & 0.35 & & \\
4. Interaction frequency & 10 & 3.09 & 1.14 & 0.33 & 0.34 & 0.41 & \\
5. Interaction quality & $3(13)^{\star *}$ & 4.82 & 0.99 & 0.33 & 0.60 & 0.45 & 0.45
\end{tabular}

Notes: * For all correlations $p<0.01$; ${ }^{\star \star}$ Interaction quality is a second order construct; its three dimensions are calculated as the mean over $4 / 5 / 4$ items 
Table II Measurement model

Constructs and items

Members' motivation

I participate in the community to learn new things

to pass on my own knowledge

to improve my career prospects

to make progress with certain projects

because it makes my work easier

to improve my contact with colleagues

Community leader

Leading the community

Motivating the members

Planning and organizing the community

Coaching and support

Communication/information

Specialist support

Management support $(0.92 / 75 \%)^{a}$

The management is aware of the importance of the community's work

The management supports the community's work by providing

resources

The management speaks positively to others about the activities of the community

My supervisor supports the work of the community

Interaction frequency

Face-to-face meeting subgroup

Face-to-face meeting whole group

Conference call

Phone calls with individual members

Video conference

Virtual collaboration (net meeting)

Chat

Discussion forum/News board

E-mail/Mailing list

Knowledge base/Community workspace

Interaction quality

Trust (4 items; 0.89/75.4\% ${ }^{\mathrm{b}}$

Cohesion (5 items; 0.90/70.5\%)

Communication climate (4 items; 0.87/71.5\%)

Notes: ${ }^{a}$ Composite reliability/AVE; ${ }^{b}$ Cronbach's alpha/explained variance
Weights loadings

N

t-statistics

0.07

0.25

0.10

0.50

0.31

0.55

0.31

0.24

1.16

2.97

1.61

1.13

0.25

0.37

0.22

$-0.02$

0.05

0.33

0.96

1.54

0.82

0.09

0.19

1.65

0.90

59.97

0.88

45.81

0.89

50.00

0.79

23.79

0.18

0.82

0.09

0.59

$-0.06$

0.28

0.25

1.24

$-0.12$

0.36

0.71

0.03

1.92

0.05

0.17

0.46

0.25

2.71

$0.14 \quad 0.76$

0.17

0.44

1.10

0.61

2.49

3.92

Table III Structural model values, path coefficients, $t$-values and test of hypotheses

\begin{tabular}{|c|c|c|c|c|c|}
\hline Dependent variable & Predictor & Hypothesis & Path Coefficient & t-values & Conclusion \\
\hline \multirow[t]{3}{*}{ Interaction frequency $\left(R^{2}=0.25\right)$} & Members' motivation & $\mathrm{H} 1 \mathrm{a}$ & $0.22^{*}$ & 1.99 & \\
\hline & Community leader & $H 1 b$ & $0.19^{\star}$ & 1.97 & \\
\hline & Management support & $\mathrm{H} 1 \mathrm{C}$ & $0.29^{\star \star \star}$ & 3.82 & H1 supported \\
\hline \multirow[t]{3}{*}{ Interaction quality $\left(R^{2}=0.47\right)$} & Members' motivation & $\mathrm{H} 2 \mathrm{a}$ & 0.12 & 1.26 & \\
\hline & Community leader & $\mathrm{H} 2 \mathrm{~b}$ & $0.44^{\star * *}$ & 6.17 & \\
\hline & Management support & $\mathrm{H} 2 \mathrm{C}$ & $0.21^{\star \star}$ & 3.13 & H2 partly supported \\
\hline Interaction quality & Interaction frequency & $H 3$ & $0.17^{\star \star}$ & 2.61 & H3 supported \\
\hline
\end{tabular}


antecedents on interaction frequency, is supported by the data. Members' motivation (0.22), community leader (0.19) and management support (0.29) significantly support interaction frequency. $\mathrm{H} 2$ is only partly supported. While interaction quality is significantly enhanced by the community leader (0.44) and management support (0.17), such an effect can not be detected for members' motivation to participate in the CoP. H3 suggests a positive relationship between interaction frequency and interaction quality. This hypothesis is supported by the data $(0.17)$.

\section{Discussion}

This study intends to enhance our understanding of the characteristics of interaction processes in CoPs and their antecedents. Building on prior research on CoPs, teams, and knowledge management the author develops and tests a research framework capturing to what extent members' motivation, the community leader and management support influence $\mathrm{CoP}$ interaction quality. Further, she investigates how interaction frequency mediates the relationship between antecedents and interaction quality. In order to test the proposed hypotheses data from 222 members of 36 communities in one multinational corporation is used.

By definition, CoPs are semi-formal entities where individuals participate mainly voluntarily. Thus, the "carrot-and-stick" approach can not be used to motivate knowledge workers to participate in CoPs. Motivated above all by intrinsic objectives individuals will only interact with other members of a CoP as long as they profit from it and experience reciprocal rewards (Ellis et al., 2004). As the results of this analysis show, individuals are mainly motivated by benefits regarding their work task and their network in the formal organization, i.e. they participate in order to progress with certain projects, to improve their career prospects, to make their work easier and to improve their contact with colleagues. Interestingly, learning purely "for the sake of it" and passing on one's own knowledge are not relevant objectives. As proposed members' motivation influence the frequency of interactions in CoPs. Contrary to the proposed hypothesis the results do not indicate a significant relationship between members' motivation and interaction quality. This can be explained by the fact that trust, cohesion and a positive communication climate exist independently of individual motivation to participate. Or in other words: less motivated members will not actively take part in the exchange and, therefore, will not influence the quality of interactions within a CoP (Wenger, 1998b). Further, the focus on CoPs in the context of corporate practice can be a reason for these findings.

Evidently, the community leader plays a central role for the interaction quality in CoPs (Moran and Weimer, 2004; Wenger, 1998a). In particular his/her ability to motivate people to interact with each other as well as his/her competences regarding the topic of the CoP have strong impact on interaction quality. This person can be regarded as a facilitator, i.e. an enabler for trust, cohesion and a positive communication climate within the CoP. Interaction quality is positively, but to a lesser extent influenced by management support. A strong leader seems to be the main predictor of interaction quality, whereas the frequency of interactions between community members is mostly dependent on an active management support. To summarize, knowledge workers in CoPs are motivated by intrinsic objectives, but they will be encouraged to interact with each other:

- by an active and supportive leader, who is an expert in the CoP's competence area; and

- by an appropriate management support which takes into account that people are motivated but need an encouraging environment and culture promoting knowledge sharing (see Zboralski, 2007 for a detailed discussion).

The results of this study have several implications for the management of knowledge workers in CoPs in corporate practice. As CoPs are fertile organizational forms, managers have to learn to cultivate them without destroying them (Wenger et al., 2002). While interfering in interactions of community members will be contra-productive, management should have an awareness of networks of knowledge workers. As this research shows, CoPs profit from an active support in terms of providing required resources, i.e. time for members to participate, 
"While interfering in interactions of community members will be contra-productive, management should have an awareness of networks of knowledge workers."

technical infrastructure, and establishing the necessary prerequisites in the organization, i.e. awareness of the importance of knowledge sharing. Further, the results indicate that the extent the community leader handles successfully his/her tasks plays a major role for the interaction quality in CoPs. Thus, management should either nominate the "right" person (for purposely initiated CoPs) or let community leaders actively improve their leadership skills, e.g. by participation in further development measures (for self-emerging CoPs). In the long term, organizations will only be able to survive and maintain their competitiveness in the knowledge-based economy if they manage the organizational and cultural change necessary (e.g., Nonaka and Takeuchi, 1995).

With regard to further CoP research, the developed scales allow a rigorous test of the hypotheses and may serve as a basis for future empirical studies. The results emphasize the importance of different antecedents of interaction processes in CoPs. Further, the author is able to present a multi-dimensional measurement of interaction quality in CoPs. In analyzing the frequency and quality of interactions within CoPs she does not control for what is actually transferred between the members. Future research could enhance our understanding of learning and knowledge generation by also considering the type of knowledge handled in the CoP. Furthermore, with respect to leadership issues the impact of existing reward schemes on members' motivation and their actual participation on knowledge sharing processes could be an interesting research area. Additionally, as this analysis is based on community members' perceptions, further studies could include assessments from community leaders.

\section{References}

Allen, T.J. and Cooney, S. (1973), "Institutional roles in technology transfer: a diagnosis of the situation in one small country", R\&D Management, Vol. 4 No. 1, pp. 41-51.

Andriessen, J.H.E. and Verburg, R.M. (2004), "The development and application of the community assessment toolkit", paper presented at 5th European Conference on Organizational Knowledge, Learning and Capabilities, Innsbruck.

APQC (2000), Building and Sustaining Communities of Practice: Final Report, American Productivity \& Quality Center, Houston, TX.

Ardichvili, A., Page, V. and Wentling, T. (2003), "Motivation and barriers to participation in virtual knowledge-sharing communities of practice", Journal of Knowledge Management, Vol. 7 No. 1.

Belsley, D.A. (1991), Conditioning Diagnostics: Collinearity and Weak Data in Regression, John Wiley \& Sons, New York, NY.

Bogenrieder, I. and Nooteboom, B. (2004), "Learning in groups: what types are there? A theoretical analysis and an empirical study in a consultancy firm", Organization Studies, Vol. 25 No. 2, pp. 287-313.

Bollen, K.A. (1989), Structural Equations with Latent Variables, Wiley, New York, NY.

Brown, J.S. and Duguid, P. (1991), "Organizational learning and communities-of-practice: toward a unified view of working, learning, and innovation", Organization Science, Vol. 2 No. 1, pp. 40-57.

Chin, W.W. (1998), "The partial least squares approach to structural equation modeling", in Marcoulides, G.A. (Ed.), Modern Methods of Business Research, Lawrence Erlbaum Associates, Mahwah, NJ; London, pp. 295-336.

Churchill, G.A. (1979), "A paradigm for developing better measures of marketing constructs", Journal of Marketing Research, Vol. 16, pp. 64-73.

VOL. 13 NO. 32009 |JOURNAL OF KNOWLEDGE MANAGEMENT | PAGE 99 
Costa, A.C., Roe, R.A. and Taillieu, T. (2001), "Trust within teams: the relation with performance effectiveness", European Journal of Work and Organizational Psychology, Vol. 10 No. 3, pp. 225-44.

Davenport, T.H. and Prusak, L. (1998), Working Knowledge: How Organizations Manage What They Know, Harvard Business School Press, Boston, MA.

Davenport, T.H., DeLong, D.W. and Beers, M.C. (1998), "Successful knowledge management projects", Sloan Management Review, Vol. 39 No. 2, pp. 43-57.

Diamantopoulos, A. and Winklhofer, H.M. (2001), "Index construction with formative indicators: an alternative to scale development", Journal of Marketing Research, Vol. 38 No. 2, pp. 269-77.

Ellis, D., Oldridge, R. and Vasconcelos, A. (2004), "Communitiy and virtual community", Annual Review of Information Science and Technology, Vol. 38, pp. 145-86.

Gherardi, S., Nicolini, D. and Odella, F. (1998), "Toward a social understanding of how people learn in organizations", Management Learning, Vol. 29 No. 3, pp. 273-97.

Gladstein, D.L. (1984), "Groups in context: a model of task group effectiveness", Administrative Science Quarterly, Vol. 29 No. 4, pp. 499-517.

Gongla, P. and Rizzuto, C.R. (2001), "Evolving communities of practice: IBM global services experience", IBM Systems Journal, Vol. 40 No. 4, pp. 842-62.

Govindarajan, V. and Gupta, A.K. (2001), "Building an effective global business team", MIT Sloan Management Review, Vol. 42 No. 4, pp. 63-71.

Guzzo, R.A. and Shea, G. (1992), "Group performance and intergroup relations in organizations", in Dunnette, M.D. and Hough, L.M. (Eds), Handbook of Industrial and Organizational Psychology, Consulting Psychologists Press, Palo Alto, CA, pp. 269-313.

Hansen, J.R., Nohria, N. and Tierney, T. (1999), "What's your strategy for managing knowledge?", Harvard Business Review, March-April, pp. 106-16.

Hauschildt, J. and Salomo, S. (2007), Innovationsmanagement, Vahlen, München.

Hislop, D. (2003), "The complex relations between communities of practice and the implementation of technological innovations", International Journal of Innovation Management, Vol. 7 No. 2, pp. 163-88.

Hoegl, M. and Gemuenden, H.G. (2001), "Teamwork quality and the success of innovative projects: a theoretical concept and empirical evidence", Organization Science, Vol. 12 No. 4, pp. 435-49.

Holland, S., Gaston, K. and Gomes, J. (2000), "Critical success factors for cross-functional teamwork in new product development", International Journal of Management Reviews, Vol. 2 No. 3, pp. 231-59.

Homans, G.C. (1960), Theorie der sozialen Gruppe, Westdeutscher Verlag, Köln.

Hulland, J. (1999), "Use of partial least squares (PLS) in strategic management research: a review of four recent studies", Strategic Management Journal, Vol. 20, pp. 195-204.

Inkpen, A.C. and Tsang, E.W.K. (2005), "Social capital, networks, and knowledge transfer", Academy of Management Review, Vol. 30 No. 1, pp. 146-65.

Jarvenpaa, S.L. and Leidner, D.E. (1999), "Communication and trust in global virtual teams", Organization Science, Vol. 10 No. 6, pp. 791-815.

Kimble, C. and Hildreth, P. (2005), "Dualities, distributed communities of practice and knowledge management", Journal of Knowledge Management, Vol. 9 No. 4, pp. 102-13.

Lave, J. and Wenger, E. (1991), Situated Learning: Legitimate Peripheral Participation, Cambridge University Press, Cambridge.

Lesser, E.L. and Storck, J. (2001), "Communities of practice and organizational performance", IBM Systems Journal, Vol. 40 No. 4, pp. 831-41.

McGrath, J.E. (1964), Social Psychology: A Brief Introduction, Holt, Rinehart and Winston Inc., London, New York, Sydney, Toronto.

Mertins, K., Heisig, P. and Vorbeck, J. (2001), Knowledge Management - Best Practices in Europe, Springer, Berlin.

PAGE 100 | JOURNAL OF KNOWLEDGE MANAGEMENT| VOL. 13 NO. 32009 
Mohrman, S.A., Finegold, D. and Mohrmann, A. Jr. (2003), "An empirical model of the organization knowledge system in new product development firms", Journal of Engineering and Technology Management, Vol. 20 Nos 1-2, pp. 7-38.

Moran, J. and Weimer, L. (2004), "Creating a multi-company community of practice for chief information officers", in Hildreth, P. and Kimble, C. (Eds), Knowledge Networks: Innovation through Communities of Practice, Idea Group, Hershey, PA, pp. 125-32.

Moray, N. (1997), "Models of models of ... mental models", in Sheridan, T.B. and Van Luntern, T. (Eds), Perspectives on the Human Controller: Essays in Honor of Henk G. Stassen, Erlbaum, Mahwah, NJ, pp. 271-85.

Nonaka, I. and Takeuchi, H. (1995), The Knowledge-creating Company: How Japanese Companies Create the Dynamics of Innovation, Oxford University Press, New York, NY.

North, D.C. (1996), Empirical Studies in Institutional Change, Cambridge University Press, Cambridge.

Pan, S.L. and Scarbrough, H. (1998), "A socio-technical view of knowledge-sharing at Buckman Laboratories", Journal of Knowledge Management, Vol. 2 No. 1, pp. 55-66.

Probst, G.J.B., Raub, S. and Romhardt, K. (1999), Wissen managen: Wie Unternehmen ihre wertvollste Ressource optimal nutzen, Frankfurter Allgemeine Zeitung; Gabler, Frankfurt a.M., Wiesbaden.

Snyder, W.M. (1999), Organization and World Design: The Gaia's Hypotheses, Social Capital Group, Cambridge, MA.

Teigland, R. (2003), Knowledge Networking: Structure and Performance in Networks of Practice, Institute of International Business, Stockholm School of Business, Stockholm.

Teigland, R. and Wasko, M.M. (2004), "Extending richness with reach: participation and knowledge exchange in electronic networks of practice", in Hildreth, P.M. and Kimble, C. (Eds), Knowledge Networks: Innovation through Communities of Practice, Idea Group, Hershey, PA, pp. 230-42.

Thompson, M. (2005), "Structural and epistemic parameters in communities of practice", Organization Science, Vol. 16 No. 2, pp. 151-64.

von Krogh, G. (1998), "Care in knowledge creation", California Management Review, Vol. 40 No. 3, pp. 133-53.

von Krogh, G. (2002), "The communal resource and information systems", Journal of Strategic Information Systems, Vol. 11, pp. 85-107.

Wasko, M.M. and Faraj, S. (2000), "'it is what one does': why people participate and help others in electronic communities of practice", Journal of Strategic Information Systems, Vol. 9, pp. 155-73.

Wenger, E.C. (1998a), "Communities of practice - learning as a social system", The Systems Thinker, Vol. 9 No. 5, pp. 1-5.

Wenger, E.C. (1998b), Communities of Practice: Learning, Meaning and Identity, Cambridge University Press, Cambridge.

Wenger, E.C., McDermott, R. and Snyder, W.M. (2002), Cultivating Communities of Practice: A Guide to Managing Knowledge, Harvard Business School Press, Boston, MA.

Zboralski, K. (2007), Wissensmanagement durch Communities of Practice. Eine empirische Analyse von Wissensnetzwerken, Deutscher Universitäts-Verlag, Wiesbaden.

\section{Corresponding author}

Katja Zboralski can be contacted at: k.zboralski@gmx.net

To purchase reprints of this article please e-mail: reprints@emeraldinsight.com Or visit our web site for further details: www.emeraldinsight.com/reprints 